Short notes and reviews

\title{
Some observations on biology and feeding behavior in two southern California pycnogonids
}

\author{
Bonnie Bain \\ Entomology Department, American Museum of Natural History, Central Park West at 79th Street, New \\ York, New York 10024-5192, USA
}

Keywords: Pycnogonida, feeding behavior, Anoplodactylus, Ammothea, laboratory conditions

\begin{abstract}
During the years 1980 to 1982 , two common southern California pycnogonids, Anoplodactylus californicus Hall, 1912 and Ammothea hilgendorfi (Böhm, 1879) were routinely collected and kept in aquaria. Observations were made both in the field and in the laboratory on feeding behavior and other aspects of the behavior and biology of the two species. It was concluded that, of the two species, Anoplodactylus californicus would be a good candidate to raise in the laboratory for further studies on the biology of these organisms.
\end{abstract}

During 1980-1982, I had the opportunity to collect and observe two common southern California pycnogonids: Anoplodactylus californicus Hall, 1912 and Ammothea hilgendorfi (Böhm, 1879). During this time, I made a number of new observations on the biology and feeding behavior of these two species.

\section{Anoplodactylus californicus Hall, 1912}

Syn.: Anoplodactylus portus Calman, 1927. (Re-examination and redescription of Hall's long mislaid type-material by Child (1987) indicated that the common pantemperate-pantropic $A$. portus is a junior synonym of this inappropriately named species.)

This species was found in great abundance at False Point, La Jolla, California, a rocky beach that is covered by water at high tide. The rocks are covered with coralline algae and hundreds of $A$. californi- cus were found living on and among the algae. At low tide, they are completely invisible. They have the same color as the coralline algae and they position themselves on the algae-covered rocks with the legs folded up around them, and remain motionless until high tide.

Some of these animals were put into a salt-water aquarium for further observation. Two of them immediately began feeding on a lamellarian gastropod, Pleurobranchus digueti Rochebrune, 1895. This is a bright orange prosobranch snail commonly known as an ear shell. While alive, it is covered by its brightly colored mantle. When dead, all that is left is an ear-shaped white shell. This particular lamellarian was found on a bright orange colonial tunicate from Quivera Basin, San Diego. The two pycnogonids feeding on it used only their mouths at first. The next day, one of them was observed carrying a piece of the lamellarian in its chelicerae.

A. californicus were also given pieces of Mytilus edulis to eat. The following is one observation of the events that occurred on January 20, 1982 after placing several pieces of Mytilus edulis in the tank: After half an hour, one large $A$. californicus moved 6 inches towards the pieces of mussel and after some hesitation (during which it lay on its back and moved its legs back and forth) began feeding on a mussel piece. It clasped the piece in its chelicerae and inserted its proboscis into it.

$A$. californicus also fed readily on brine shrimp. These were added to the tank regularly. As soon as the brine shrimp were put in the tank, the pyc- 
nogonids began feeding on them. When a brine shrimp swam by, the pycnogonid reached out and grabbed it in its chelicerae. They were very fast and very accurate in these movements. Contrary to popular belief, this pycnogonid can move very quickly. It was not possible to follow by eye the rapid movements of the chelicerae as they reached out for the brine shrimp. This is the first record of a sea-spider feeding on a rapidly moving prey.

Once the brine shrimp was secured in the chelicerae, the pycnogonid placed its mouth onto the brine shrimp. It was not possible to observe the actions of the mouth. The pycnogonid usually held the brine shrimp in this position and fed on it for an average time of 2-3 hours before discarding it.

While these pycnogonids were in the tank, they also reproduced. The tank had not been watched for several days, so it was not possible to observe the unexpected mating event. Previous to this, none of the males were carrying eggs. Then one day, all of them were. This species would be an ideal candidate for further observations both of feeding and mating behavior since it is so easy to maintain in the laboratory.

\section{Ammothea hilgendorfi (Böhm, 1879)}

During 1980-1982, A. hilgendorfi was found in great abundance on the floating docks at Dana Marina in Mission Bay, San Diego. Hundreds of these could be collected on any given day. They were most frequently found on the byssal threads of Mytilus edulis where they were perfectly camouflaged. It was impossible to see this pycnogonid on the byssal threads until it moved.

$A$. hilgendorfi was kept in an aquarium separate from Anoplodactylus californicus. Unlike A. californicus, Ammothea hilgendorfi was never observed to feed on anything. Pieces of mussel and brine shrimps were offered to them without result. They lived for several months in the aquarium and then died.

Both ovigerous males and mature females were found year round. Periodically, while in the aquarium, eggs on ovigerous males hatched. The protonymphon larvae, after hatching, dropped down to the glass bottom of the tank and scurried rapidly away from the parent. They appeared to be searching for something, possibly a hydroid or other suitable host. Not being provided with the appropriate host, they survived, on average, only two weeks in the laboratory.

Even though $A$. hilgendorfi did not feed in the laboratory, one could observe frequent gut peristalsis in each animal. This was most easily visible in the walking legs. Periodically, a wave of peristalsis passed from the body and out through the leg, ending just before the tarsus.

Circulation of the blood was also clearly visible in this pycnogonid. On the ventral side of the body, blood always flowed in a posterior direction, from the proboscis back towards the body. Throughout the rest of the body, it flowed in one direction for a while, then reversed and flowed in the opposite direction. These observations agree with Cole's observations on Endeis spinosus (Montagu, 1808) (cf. Cole, 1910). The blood is clear and contains many small white particles.

On February 7, 1982, A. hilgendorfi was found on the bay side of Mission Bay Jetty. They were found in moist eelgrass and rubble at the high tide line, under small rocks. Low tide that day was at 3:15 P.M. The pycnogonids were discovered at the high tide line between 5:00 and 5:30 P.M. They had been out of the water at that point for 6-8 hours. The animals themselves appeared to be completely dry. Several were taken back to the laboratory and placed in an aquarium. Drying out appeared to have had no adverse effects on them. Perhaps this is a daily occurrence. It is interesting that this particular species can occur in such diverse habitats as a floating dock (where it is completely submerged) and a rocky beach (where it appears to dry out daily during low tide).

\section{References}

Child, C.A., 1987. The Pycnogonida types of H.V.M. Hall. Proc. biol. Soc. Wash., 100(3): 552-558.

Cole, L.J., 1910. Peculiar habitat of a pycnogonid (Endeis spinosus) new to North America, with observations on the heart and circulation. Biol. Bull., 18(4): 193-203.

Received: 13 February 1990

Revised: 10 March 1991 